\title{
Tools to kill: Genome of one of the most destructive plant pathogenic fungi Macrophomina phaseolina
}

\author{
Md Shahidul Islam, Md Samiul Haque ${ }^{1}$, Mohammad Moinul Islam, Emdadul Mannan Emdad', Abdul Halim , \\ Quazi Md Mosaddeque Hossen', Md Zakir Hossain', Borhan Ahmed', Sifatur Rahim', Md Sharifur Rahman', \\ Md Monjurul Alam', Shaobin Hou², Xuehua Wan², Jennifer A Saito ${ }^{3}$ and Maqsudul Alam ${ }^{1,2^{*}}$
}

\begin{abstract}
Background: Macrophomina phaseolina is one of the most destructive necrotrophic fungal pathogens that infect more than 500 plant species throughout the world. It can grow rapidly in infected plants and subsequently produces a large amount of sclerotia that plugs the vessels, resulting in wilting of the plant.

Results: We sequenced and assembled $\sim 49 \mathrm{Mb}$ into 15 super-scaffolds covering 92.83\% of the M. phaseolina genome. We predict 14,249 open reading frames (ORFs) of which 9,934 are validated by the transcriptome. This phytopathogen has an abundance of secreted oxidases, peroxidases, and hydrolytic enzymes for degrading cell wall polysaccharides and lignocelluloses to penetrate into the host tissue. To overcome the host plant defense response, M. phaseolina encodes a significant number of P450s, MFS type membrane transporters, glycosidases, transposases, and secondary metabolites in comparison to all sequenced ascomycete species. A strikingly distinct set of carbohydrate esterases (CE) are present in M. phaseolina, with the CE9 and CE10 families remarkably higher than any other fungi. The phenotypic microarray data indicates that $M$. phaseolina can adapt to a wide range of osmotic and $\mathrm{pH}$ environments. As a broad host range pathogen, $M$. phaseolina possesses a large number of pathogen-host interaction genes including those for adhesion, signal transduction, cell wall breakdown, purine biosynthesis, and potent mycotoxin patulin.

Conclusions: The M. phaseolina genome provides a framework of the infection process at the cytological and molecular level which uses a diverse arsenal of enzymatic and toxin tools to destroy the host plants. Further understanding of the $M$. phaseolina genome-based plant-pathogen interactions will be instrumental in designing rational strategies for disease control, essential to ensuring global agricultural crop production and security.
\end{abstract}

Keywords: Genome sequencing, Phytopathogens, Charcoal rot, Phenotypic microarray

\section{Background}

Macrophomina phaseolina, a global devastating necrotrophic fungal pathogen, infects more than 500 plant hosts [1]. It includes major food crops (maize, sorghum [2]), pulse crops (common bean [3], green gram [4]), fiber crops (jute [5], cotton [6]), and oil crops (soybean

\footnotetext{
* Correspondence: maqsudul@jutegenome.org

'Basic and Applied Research on Jute Project, Bangladesh Jute Research Institute, Manik Mia Avenue, Dhaka 1207, Bangladesh

${ }^{2}$ Advanced Studies in Genomics, Proteomics and Bioinformatics, University of Hawaii, 2565 McCarthy Mall, Keller 319, Honolulu, Hawaii 96822, USA

Full list of author information is available at the end of the article
}

[1], sunflower [7], sesame [8]). Despite its wide host range, Macrophomina is a monotypic genus [9].

Diseases caused by M. phaseolina (e.g., seedling blight, charcoal rot, stem rot, and root rot) are favored with higher temperatures $\left(30-35^{\circ} \mathrm{C}\right)$ and low soil moisture [10]. It is difficult to control M. phaseolina due to its persistence as sclerotia in the soil and plant debris [11]. Recently, increased incidence of the pathogen on diverse crop species has been reported worldwide [12-14], highlighting the importance of this disease to crop production in drought prone regions.

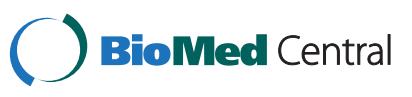


The fungus has a wide geographical distribution, and is especially found in tropical and subtropical countries with arid to semi-arid climates in Africa, Asia, Europe, and North and South America [15-17]. This pathogen can result in severe crop losses. For example, charcoal rot is a serious problem of soybean, which accounted for a total yield loss of $\$ 173.80$ million in the United States during 2002 [18]. In Bangladesh, the fiber yield of jute is reduced by $30 \%$ due to this pathogen.

$M$. phaseolina is an anamorphic fungus in the ascomycete family Botryosphaeriaceae. The fungus can remain viable for more than 4 years in soil and crop residue as sclerotia (Figure 1a) [11]. The M. phaseolina hyphae initially invade the cortical tissue of jute plants, followed by sclerotia formation, causing stem rot disease (Figure 1b, c). Gray-black mycelia and sclerotia are produced (Figure 1c) and the infected area exhibits disease symptoms (Figure 1d). The conidia are hyaline, aseptate, thin-walled, and elliptical (Figure 1e). Under favorable conditions, hyphae germinate from the sclerotia and infect the roots of the host plant by penetrating the plant cell wall through mechanical pressure and/or chemical softening [19]. The disease progresses from leaf yellowing to wilting and ultimately plant death (Figure 1f).

Currently, genetic information on $M$. phaseolina is scarce with only 176 expressed sequence tags (ESTs) and 903 nucleotide sequences in the National Center for Biotechnology Information (NCBI). Here we report the draft genome sequence of highly destructive plant pathogen $M$. phaseolina to gain insight into the molecular basis of pathogenesis.

\section{Results and discussion}

\section{Genome sequencing and assembly}

The genome of $M$. phaseolina was sequenced using a whole-genome shotgun approach. A total of $6.92 \mathrm{~Gb}$ of
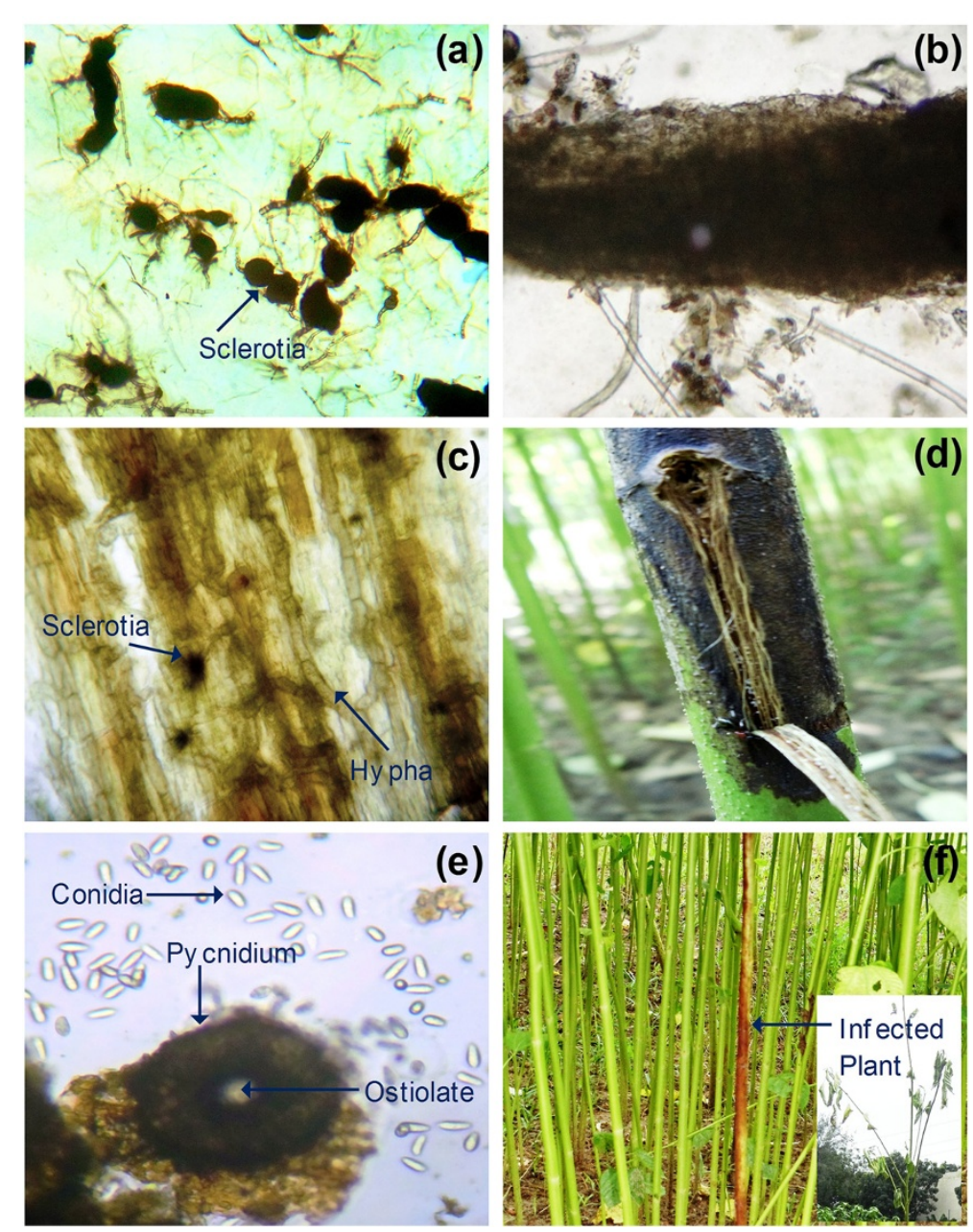

Figure 1 Infection of jute by $\mathbf{M}$. phaseolina. (a) Stereomicrograph of sclerotia that exists in soil and crop residue. (b) Pathogen produces extensive and profuse aerial hyphae to invade the stem bark. (c) Longitudinal section of stem bark showing inter- and intracellular mycelium and sclerotia. (d) During early rainy season, hyphae penetrate the plant cell wall and produce disease symptoms. (e) Light micrograph of globose ostiolate pycnidia and spores of M. phaseolina. (f) Diseased plants showing infection of the stem, which eventually wilt and prematurely die (Inset). 
raw sequence was generated from a combination of 454 and Illumina platforms (Additional file 1: Table S1). The resulting assembly is $49.29 \mathrm{Mb}$ of which $98.53 \%$ is nongapped sequence (Table 1; Additional file 1: Table S2). Mapping with Newbler GS Reference Mapper (v2.5.3) showed $96.50 \%$ reads and $99.11 \%$ bases mapped to the reference assembly. The draft genome sequence consists of 94 scaffolds, with 15 super scaffolds covering $92.83 \%$ of the total assembled length (Additional file 1: Table S2). We predicted 14,249 protein-coding genes and 9,934 were validated by the transcriptome (Additional file 1: Table S3).

We examined the homology between M. phaseolina and 12 other fungal genomes under the classes of Saccharomycetes, Sordariomycetes, Agaricomycetes, and Eurotiomycetes. The results revealed that $71 \%$ of the genes in the $M$. phaseolina genome have homologs in other fungal genomes and the remaining $29 \%$ are orphan genes (Figure 2a). Among the orphan genes, $51.11 \%$ are found in the transcriptome.

The comparison of $M$. phaseolina protein families with other ascomycete fungal species is shown in Table 2 (also see Additional file 1: Table S4). The genome contains $13.07 \%(1,863)$ secreted proteins as compared to $7-10 \%$ in other plant pathogens [20]. Surprisingly, M. phaseolina has the lowest number of proteases among ascomycete fungal species [21] (Table 2). On the other hand, the genome is distinct from other fungi by having the highest number of cytochrome P450, glycosidase, and secondary metabolite backbone genes. We predict that this might be one of the main strategies of $M$. phaseolina to overcome the host plant defense response by using various secondary metabolites.

Table 1 Genome assembly and annotation statistics

\begin{tabular}{ll}
\hline Genome features & MS6 \\
\hline Strain & 13 \\
Sequence coverage (fold) & 49.295 \\
Genome Size (Mb) & 94 \\
Total scaffolds & 15 \\
No. of scaffolds ( $\geq 1 \mathrm{Mb})$ & 3.39 \\
N50 scaffold length (Mb) & 6 \\
Number of N50 scaffolds & 14,249 \\
Number of genes & 14,071 \\
No. of genes in 15 scaffolds ( $\geq 1 \mathrm{Mb})$ & 9,934 \\
Number of genes found in cDNA & 1,265 \\
Median gene length (bp) & 2.84 \\
Repetitive sequence (\%) & 3.98 \\
Transposable elements (\%) & AHHD00000000 \\
NCBl accession &
\end{tabular}

\section{Conserved syntenic and phylogenetic relationship}

Pairwise comparison revealed that the genome structures of M. phaseolina and Fusarium oxysporum, one of the most important phytopathogenic and toxigenic fungi, have large areas of synteny (Figure 2b). Among the $14,249 \mathrm{M}$. phaseolina genes, 7,767 (54.10\%) are shared with $F$. oxysporum (Additional file 2: Figure S1). The large number of shared genes may reflect common strategies for infecting a remarkably broad host range. Ninety seven percent of the $M$. phaseolina genome comprises non-repetitive sequences, and the orthologs shared with the $F$. oxysporum genome display an average $52 \%$ identity. A phylogenetic analysis revealed the evolutionary relationship among fungal taxa and the positioning of $M$. phaseolina within the pezizomycotina (Figure 2c).

\section{Global paralog network}

Of the 14,249 predicted proteins, we found homologs for 7,999 proteins in nine fungal genomes. To characterize functional protein families in the $M$. phaseolina genome, we constructed a database in Pathway Studio (Ariadne Genomics Inc.) containing M. phaseolina proteins with functional annotation from the orthologs in nine other fungal genomes, predicted interologs, predicted pathways, and paralog network. The largest paralog families were identified by clustering the paralog network consisting of 6,210 paralog links representing paralog pairs with sequence homology above $30 \%$. We identified 77 paralog families having more than six proteins (Additional file 2: Figure S2). The larger paralog families were the cytochrome P450 (151), MFS type membrane transporters (222), and transposases (101). The large number of transposons in the $M$. phaseolina genome suggests that they could be the primary mechanism for mutagenesis and gene duplications, which in turn may promote the ability of $M$. phaseolina to infect new plant species.

There was also a high number of paralogs for the oxido-reductase class of enzymes which includes dehydrogenases, aldehyde dehydrogenases, choline dehydrogenases, cytochrome P450 and aldose reductases. These oxido-reductase enzymes produce and utilize a large variety of secondary metabolites [22] which may trigger $M$. phaseolina to survive in a wide range of physical environments and facilitate to infect new plant species. The PTH11 paralog family consists of a large number of G-protein coupled receptors (GPCR; 44), which contain a cysteine-rich fungal extracellular membrane domain. This may facilitate $M$. phaseolina to be more virulent.

\section{Repetitive DNA and transposable elements}

Wide virulence capabilities of a genome are often associated with transposon-mediated inactivation or deletion 


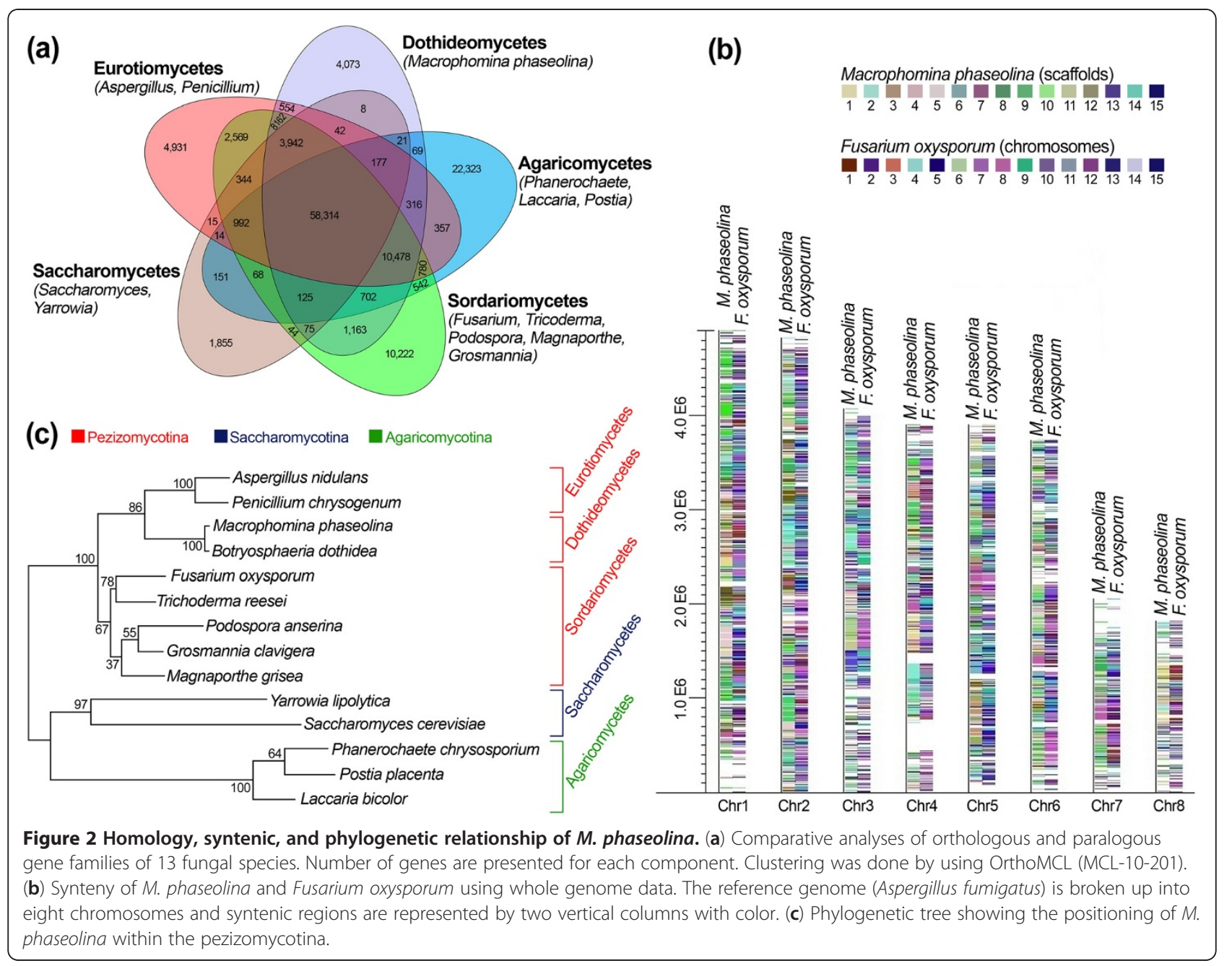

of pathogen-associated molecular pattern (PAMP)encoding genes whose products trigger the plant adaptive immune system [23]. The M. phaseolina genome comprises $2.84 \%$ repetitive DNA and 3.98\% transposable elements. The transposable elements are classified into 11 families (Table 3). Most of them are DNA transposases, with particular abundance of the subclasses gypsy (918), Ty1_Copia (331), and DDE_1 (242). LINE (184) and hAT (136) are also relatively abundant. Transposable elements appear to be tightly clustered in the genome (Additional file 2: Figure S3). Evidence for repeat-induced point mutation (RIP) within the transposable elements was searched using RIPCAL [24], but this mutational bias was not observed in the $M$. phaseolina genome (RIP index 0.87). The genome contains more fragmented pseudogenes (894) than processed pseudogenes (31) caused by mobile elements, but lacks duplicated pseudogenes. This is consistent with transposons making a greater contribution to genetic instability in M. phaseolina.

\section{Carbohydrate degrading enzymes}

Phytopathogenic fungi secrete a cocktail of hydrolytic enzymes (including carbohydrate-active enzymes; CAZymes) for degrading the plant cell wall and penetrating into the host tissue [25]. The M. phaseolina genome encodes 362 putative CAZymes including 219 glycoside hydrolases (GH), 56 glycosyltransferases (GT), 65 carbohydrate esterases (CE), 6 carbohydrate binding modules (CBM), and 16 polysaccharide lyases (PL) comprising more than 80 distinct families. These enzymes do not appear to be tightly clustered, but are distributed throughout the genome (Additional file 2: Figure S4).

The number of GHs possessed by M. phaseolina is higher than the average for plant pathogenic fungi and is nearly four times more abundant than the GTs, consistent with the importance of carbohydrate degradation rather than formation. There are 25 putative endoglucanases (GH5, GH12, GH45, GH61), 7 exocellobiohydrolases (GH6, GH7, GH81), and $28 \beta$-glucosidases (GH1, GH3, GH17) for the hydrolysis of cellulose. The 
Table 2 Sizes of selected protein families in M. phaseolina and other fungi

\begin{tabular}{|c|c|c|c|c|c|c|c|c|c|c|c|}
\hline Protein family $^{a}$ & $\mathrm{MP}^{\mathrm{b}}$ & FO & FG & MO & $\mathrm{BC}$ & SS & $\mathrm{NC}$ & AN & $\mathrm{AF}$ & $\mathrm{PCH}$ & PP \\
\hline Fungal specific transcription factors & 156 & 101 & 192 & 95 & 118 & 90 & 89 & 209 & 169 & 65 & 63 \\
\hline $\mathrm{C} 2 \mathrm{H} 2$ zinc finger transcription factors & 66 & 73 & 85 & 58 & 48 & 54 & 63 & 58 & 51 & 77 & 42 \\
\hline Zn2/Cys6 transcription factors & 113 & 370 & 376 & 155 & 142 & 108 & 110 & 307 & 230 & 146 & 118 \\
\hline Major facilitator superfamily & 270 & 352 & 274 & 198 & 225 & 167 & 110 & 279 & 232 & 141 & 184 \\
\hline Cytochrome P450 & 256 & 178 & 112 & 137 & 129 & 93 & 40 & 116 & 74 & 155 & 236 \\
\hline Pth11-like G-protein coupled receptor & 44 & 55 & 51 & 60 & 22 & 23 & 28 & 39 & 15 & 14 & 26 \\
\hline Protein kinases & 140 & 160 & 129 & 129 & 124 & 164 & 111 & 127 & 131 & 106 & 56 \\
\hline Histidine kinase & 1 & 37 & 20 & 6 & 3 & 5 & 8 & 12 & 6 & 19 & 24 \\
\hline Heterokaryon incompatibility & 65 & 82 & 88 & 41 & 59 & 34 & 45 & 7 & 8 & 3 & 2 \\
\hline Serine proteases & 1 & 12 & $60 / 150^{c}$ & $56 / 91$ & $19 / 34$ & $20 / 33$ & $32 / 74$ & $53 / 136$ & $29 / 46$ & 0 & 2 \\
\hline Subtilisin & 19 & 36 & $16 / 24$ & $26 / 29$ & $4 / 7$ & $4 / 6$ & $6 / 10$ & $3 / 4$ & $3 / 7$ & 12 & 33 \\
\hline Trypsin & 2 & 3 & $2 / 3$ & $3 / 3$ & $1 / 1$ & $1 / 1$ & $0 / 2$ & $1 / 2$ & $0 / 0$ & 0 & 0 \\
\hline Carboxypeptidase & 19 & 31 & $12 / 21$ & $7 / 8$ & $7 / 9$ & $8 / 11$ & $6 / 9$ & $5 / 12$ & $14 / 15$ & 24 & 22 \\
\hline Aspartic protease & 4 & 0 & $15 / 18$ & $14 / 19$ & $11 / 14$ & $9 / 21$ & $15 / 19$ & $7 / 16$ & $7 / 9$ & 38 & 18 \\
\hline Threonine protease & 0 & 0 & $3 / 18$ & $2 / 18$ & $2 / 13$ & $2 / 13$ & $2 / 20$ & $0 / 20$ & $1 / 17$ & 0 & 0 \\
\hline Cysteine protease & 3 & 0 & $5 / 57$ & $4 / 31$ & $3 / 24$ & $1 / 27$ & $4 / 41$ & $6 / 57$ & $3 / 31$ & 0 & 0 \\
\hline Metalloprotease & 8 & 26 & $32 / 111$ & $38 / 91$ & $6 / 50$ & $7 / 48$ & $21 / 81$ & $22 / 105$ & $20 / 77$ & 0 & 0 \\
\hline All proteases & 113 & 261 & 354 & 250 & 135 & 142 & 235 & 334 & 180 & 228 & 325 \\
\hline Lipase & 53 & 61 & $4 / 31$ & $2 / 23$ & $3 / 28$ & $2 / 25$ & $0 / 16$ & $2 / 27$ & $3 / 25$ & 23 & 40 \\
\hline Esterase/thioesterase & 108 & 95 & 70 & 64 & 70 & 58 & 42 & 63 & 52 & 74 & 69 \\
\hline Glycoside hydrolase related & 219 & 168 & 159 & 198 & 120 & 126 & 137 & 200 & 165 & 180 & 144 \\
\hline Transposases & 101 & 19 & 17 & 15 & 73 & 426 & 15 & 15 & 109 & 12 & 11 \\
\hline Cutinase & 10 & 12 & 12 & 18 & 11 & 8 & 3 & 4 & 5 & 0 & 0 \\
\hline Polysaccharide lyase & 16 & 23 & 25 & 9 & 25 & 20 & 5 & 24 & 27 & 4 & 6 \\
\hline Secondary metabolite backbone genes & 75 & 34 & 37 & 32 & 37 & 29 & 15 & 58 & 40 & 51 & 39 \\
\hline
\end{tabular}

${ }^{a}$ Corresponding InterPro codes are listed in Additional file 1: Table S4.

${ }^{\mathrm{b}}$ Fungal species are MP, Macrophomina phaseolina; FO, Fusarium oxysporum; FG, Fusarium graminearum; MO, Magnaporthe oryzae; BC, Botrytis cinerea; SS, Sclerotinia sclerotiorum; NC, Neurospora crassa; AN, Aspergillus nidulans; AF, A. fumigatus; PCH, Phanerochaete chrysosporium, and PP, Postia placenta.

${ }^{\mathrm{c}}$ Fractions indicate the number of total proteins in each family that are secreted.

Table 3 Families of transposable elements in the M. phaseolina genome

\begin{tabular}{lll}
\hline Family name & Class & Number \\
\hline LTR roo & Class I & 4 \\
DDE_1 & Class I & 242 \\
gypsy & Class I & 918 \\
Ty1-Copia & Class I & 331 \\
LINE & Class I & 184 \\
hAT & Class II & 136 \\
helitron & Class II & 15 \\
cacta & Class II & 4 \\
Mariner & Class II & 76 \\
MuDR_A_B & Class II & 57 \\
piggybac & Class II & 9 \\
Total & & $\mathbf{1 9 7 6}$ \\
\hline
\end{tabular}

cellulolytic activity of $M$. phaseolina was shown to be significantly higher than that of other fungal species (i.e., Aspergillus niger and Trichoderma reesei) [26], reflecting the pathogenicity potency of this fungus.

The M. phaseolina genome also has the highest number of CEs than any other sequenced fungal genome so far (Table 4), with particular expansion of families CE9 (chitin metabolism) and CE10 (sterol esterases). Thirty two CE10 members are found in the M. phaseolina genome, but is absent in eight other species (Table 4). Nine CE5 candidate cutinases were found in the genome, suggesting that these enzymes are critical for initial penetration through the plant cuticle. The complement of pectin lyases (PL1, PL3, PL4), pectin hydrolases (GH28, GH88), and pectin esterases allows M. phaseolina to fully saccharify pectin. Other polysaccharide degrading enzymes predicted in the genome include catalytic activities for degrading starch and glycogen, hemicellulose, chitin, and $\beta$-glucans. 
Table 4 Comparison of the number of carbohydrate esterases of $M$. phaseolina with other fungi

\begin{tabular}{llllllllllllll}
\hline Name & CE1 & CE2 & CE3 & CE4 & CE5 & CE8 & CE9 & CE10 & CE12 & CE14 & CE15 & CE16 & NC \\
\hline C. neoformans var. neoformans & 2 & 0 & 0 & 4 & 0 & 0 & 1 & 0 & 0 & 0 & 0 & 0 & 0 \\
M. grisea & 10 & 1 & 6 & 8 & 15 & 1 & 1 & 0 & 2 & 0 & 1 & 1 & 1 \\
S. cerevisiae & 1 & 0 & 0 & 2 & 0 & 0 & 0 & 0 & 0 & 0 & 0 & 0 & 0 \\
P. anserina & 14 & 0 & 8 & 5 & 7 & 1 & 1 & 0 & 1 & 0 & 3 & 1 & 0 \\
A. nidulans & 3 & 0 & 6 & 7 & 4 & 3 & 1 & 0 & 2 & 0 & 0 & 3 & 4 \\
A. niger & 3 & 0 & 1 & 5 & 5 & 3 & 1 & 0 & 2 & 0 & 0 & 2 & 3 \\
A. oryzae & 5 & 0 & 3 & 3 & 5 & 5 & 1 & 0 & 4 & 0 & 0 & 3 & 1 \\
P. chrysogenum & 2 & 0 & 4 & 5 & 4 & 2 & 1 & 0 & 2 & 0 & 1 & 1 & 0 \\
M. phaseolina & 1 & 0 & 0 & 8 & 9 & 4 & 10 & 32 & 0 & 1 & 0 & 0 & 0 \\
\hline
\end{tabular}

\section{Genes involved in lignin degradation}

Major components of the lignin depolymerization system in $M$. phaseolina include laccases, lignin peroxidases, galactose oxidases, and chloroperoxidases, haloperoxidases, and heme peroxidases. $M$. phaseolina strain MS6 indeed demonstrates ligninolytic activity (Additional file 2: Figure S5). In comparison to seven other fungal species, $M$. phaseolina possesses the highest number of laccases (Table 5). Lignin peroxidase has been reported only in Phanerochaete chrysosporium thus far [27] and interestingly, this study revealed the second occurrence in $M$. phaseolina. Six extracellular class II heme peroxidases (IPR002016), 6 chloroperoxidases, and 7 haloperoxidases also contribute to the ligninolytic activity. In addition, we found a significant number of GMC oxidoreductases (40), which includes alcohol oxidases and cellobiose dehydrogenases. These enzymes are known to be directly involved in lignocellulosic degradation [27].

\section{Virulence associated genes}

As a wide host ranged pathogenic fungus, M. phaseolina is expected to possess a significant number of pathogenhost interaction genes. We searched the genome using the pathogen-host interaction database (PHI-base) [28] and identified 537 putative PHI genes (Additional file 1: Table S5). These genes play diverse roles in pathogenesis including adhesion, signal transduction, cell wall breakdown, purine biosynthesis, and biosynthesis of the potent mycotoxin patulin. ATP-binding cassette (ABC) transporters aid in defending the pathogen from hostproduced secondary metabolites as well as provide essential nutrients [29]. A number of detoxification genes are present, such as those encoding cytochrome P450 (IPR001128), Cof protein (IPR000150), and superoxide dismutase, $\mathrm{Cu} / \mathrm{Zn}$ binding (IPR001424). In addition, several beta-ketoacyl synthases (IPR000794) involved in the biosynthesis of a polyketide antibiotic [30] as well as some tetracycline resistance genes have been identified in M. phaseolina. These data suggest that the M. phaseolina genome encodes a large repertoire of pathogenicityassociated genes which may be involved in the pathogenesis of this organism.

\section{Signal transduction}

The perception of environmental cues through cellsurface receptors and relaying the information to intracellular signaling pathways is essential for pathogenicity. The PTH11-like GPCR is a PHI protein shown to regulate Magnaporthe grisea appressorium differentiation in response to the plant surface [31]. The $M$. phaseolina genome has 44 putative PTH11-like GPCRs compared to an average of 34 in other pathogenic fungi (Table 2). The putative PTH11-like GPCRs are grouped into seven

Table 5 Comparison of the number of lignin degrading enzymes of $M$. phaseolina with other fungi

\begin{tabular}{lllll}
\hline Fungal species & Laccase & Galactose oxidases & Lignin peroxidase & Chloroperoxidase \\
\hline P. placenta & 2 & 0 & 0 & 5 \\
P. chrysosporium & 0 & 0 & 10 & 3 \\
C. neoformans & 0 & 0 & 0 & 0 \\
U. maydis & 0 & 1 & 0 & 0 \\
S. cerevisiae & 0 & 0 & 0 & 0 \\
A. nidulans & 1 & 0 & 0 & 0 \\
N. crassa & 5 & 1 & 0 & 0 \\
M. phaseolina & 22 & 7 & 3 & 6
\end{tabular}


subfamilies. Three G-protein alpha subunits are present to transduce the extracellular signals leading to infection specific development, which is required for pathogenicity [32,33]. The 140 protein kinases in M. phaseolina is above the average (131) found in other ascomycete fungi (Table 2). Since signal transduction is a crucial part of fungal development and the infection process, indeed most of the kinases had orthologs in PHI-base (134/140). This result indicates that protein kinases in M. phaseolina might play a functional role in pathogen-host interaction.

\section{Transport and detoxification of compounds}

Plant pathogenic fungi use a wide range of strategies to gain access to the carbon sources of their host plants and counter the plant defense response. The M. phaseolina genome encodes 839 transporter genes comprising 106 families (Additional file 1: Table S6). Majority of the transporter genes $(782 / 839)$ were similar to those cataloged in PHI-base. A large proportion of transporters belong to the MFS family (270), but the ABC superfamily (59) and Amino Acid-Polyamine-Organocation (APC) family (40) are also well represented in the genome (Additional file 1: Table S6). M. phaseolina has more amino acid transporters (54) than other pathogenic fungi (29 to 38), revealing that this fungus might be able to access a wide range of protein degradation products from host sources. The sucrose and galactoside transporter (MFS superfamily) is required by Metarhizium anisopliae for rhizosphere competence but not for virulence [34]. The M. phaseolina genome has 15 sucrose and galactoside transporters, whereas Fusarium graminearum contains 12, suggesting these genes could be generally important for establishing plant-fungus relationships.

We found a relatively large number of genes involved in detoxification (Table 2). The dehydrogenases (411), acyl-CoA N-acetyltransferases (7), monooxygenases (104), and cytochrome P450s (256) were preferentially expanded in M. phaseolina. P450s play an important role in various hydroxylation and oxidation processes including secondary metabolism as well as the breakdown of toxins and other xenobiotic compounds [35]. For example, pisatin demethylase, a P450 from the plant pathogenic fungus Nectria haematococca, detoxifies a specific class of plant defense compounds [36]. The genome was particularly enriched in zinc-containing alcohol dehydrogenases (92) required for the biosynthesis of mannitol, a crucial factor for stress tolerance and virulence in the animal pathogen Cryptococcus neoformans [37]. The monooxygenases are generally involved in rapid elimination of plant polyphenols (which can act as antifungal agents), thus reducing the plant defense [38-40].

\section{Secondary metabolic pathways}

Plant pathogenic fungi produce diverse secondary metabolites that aid in pathogenicity, such as host selective toxins [41]. We identified 75 putative secondary metabolite genes in the M. phaseolina genome, compared with 32 in M. grisea, 37 in Botrytis cinerea, 29 in Sclerotinia sclerotiorum, and 37 in F. graminearum (Table 6). There are 35 genes predicted to encode polyketide synthases (PKS), compared with 23 PKS genes in M. grisea. An impressive number of non-ribosomal peptide synthetases (NRPS) are found in M. phaseolina, which catalyze the production of cyclic peptides including numerous toxins. Only 6 NRPS genes and 8 hybrid PKS-NRPS are present in M. grisea, whereas 28 NRPS and 12 PKS-NRPS genes are in M. phaseolina. Virulence of several fungi (e.g., Cochliobolus heterostrophus, C. miyabeanus, F. graminearum, and Alternaria brassicicola) is mediated by particular siderophores, a class of secondary metabolites for iron uptake whose synthesis involves a NRPS [42]. $M$. phaseolina contains a NRPS (contig00285) which is similar to HTS1 (46\% identity), the key enzyme responsible for the biosynthesis of the host-selective HC-toxin that confers the specificity of Cochliobolus carbonum to maize [43]. The NRPS-like proteins encoded by contig00324, contig00467, contig00109, contig00163, and contig00323 are most similar to Ace1, a PKS-NRPS

Table 6 Distribution of secondary metabolite gene families in different plant pathogenic fungi

\begin{tabular}{|c|c|c|c|c|c|}
\hline Protein family ${ }^{a}$ & M. phaseolina & M. grisea & B. cinerea & S. sclerotiorum & F. graminearum \\
\hline Secondary metabolite backbone genes & 75 & 32 & 37 & 29 & 37 \\
\hline PKS & 19 & 12 & 16 & 16 & 14 \\
\hline PKS like & 16 & 3 & 6 & 2 & 1 \\
\hline NRPS & 15 & 5 & 6 & 5 & 10 \\
\hline NRPS like & 13 & 6 & 8 & 5 & 11 \\
\hline HYBRID & 12 & 3 & 0 & 0 & 1 \\
\hline DMAT & 0 & 3 & 1 & 1 & 0 \\
\hline
\end{tabular}

${ }^{a}$ The abbreviations are PKS, polyketide synthase; NRPS, non-ribosomal peptide synthetase; HYBRID, hybrid PKS-NRPS enzyme; DMAT, dimethylallyl tryptophan synthase. 
hybrid that confers avirulence to $M$. grisea during rice infection [44].

\section{Phenotypic response in relation to different environmental stimuli}

We used Phenotype Microarray (PM) analysis (Biolog Inc.) to evaluate $M$. phaseolina against $~ 960$ different carbon, nitrogen, phosphorus, sulfur, nutrient supplement, peptide nitrogen, osmolytes, and $\mathrm{pH}$ sources (Figure 3; Additional file 2: Figures S6-S11). Of particular interest, we found that the adaptability to wide osmotic and $\mathrm{pH}$ ranges could be a contributing factor to this organism's pervasive nature.

PM analysis revealed that $M$. phaseolina is capable of growing in sodium salt concentrations of $1-8 \%$, with maximal growth at $2-4 \%$ (Figure $3 a$ ). In comparison, $3 \%$ $\mathrm{NaCl}$ is toxic for Saccharomyces cerevisiae but is close to the optimum for growth of the halophilic black yeast Hortaea werneckii, one of the most salt-tolerant eukaryotic organisms so far described [45]. The efficient utilization of various osmolytes provides clues to M. phaseolina's osmoadaptation strategy. It was recently shown that salinity increases the disease severity caused by M. phaseolina on Phaseolus vulgaris (common bean), by enhancing the growth rate of the pathogen as well as weakening the plant due to ion $\left(\mathrm{K}^{+}\right.$and $\left.\mathrm{Na}^{+}\right)$imbalance [46]. This indicates that M. phaseolina could be a greater threat in areas with saline soils.

$\mathrm{pH}$ is one of the major environmental factors affecting pathogenicity. The M. phaseolina genome contains $2 \mathrm{pu}-$ tative PalH and 5 Pall proteins which are responsible for sensing ambient $\mathrm{pH}$ [47]. Moreover, there are several $\mathrm{pH}$-regulated proteins including 19 acid phosphatases, 2 $\alpha$-L-arabinofuranosidases, and 7 alkaline phosphatases. The presence of acid and alkaline phosphatases indicates that M. phaseolina has an extraordinary capability to neutralize both acidic and alkaline environments for its growth. This is clearly evident from our PM analysis. The results revealed that $M$. phaseolina can grow in $\mathrm{pH}$ ranging from strongly acidic to alkaline ( $\mathrm{pH} 3.5$ to 10), with maximum growth between $\mathrm{pH} 5$ to 7 (Figure 3b). Therefore, M. phaseolina has a robust $\mathrm{pH}$ sensing system which enables it to adapt to adverse conditions.

\section{Pathogenesis of $M$. phaseolina}

The array of metabolic genes within the M. phaseolina genome reflects its pathogenic lifestyle (Figure 4; Additional file 1: Table S7).

The production and dispersal of conidia is important for fungal survival and infection of new hosts. Hyperosmotic stress is one of the environmental stimuli that often trigger conidiation [48]. The M. phaseolina genome encodes MPH_01444, a homolog of the MAP kinase OSM1, which regulates the osmotic stress response (to maintain cellular turgor) along with MPH_10325 and MPH_03305 (Figure 5; Additional file 1: Table S8). In $M$. grisea, deletion of OSM1 has pleiotropic effects including osmotic sensitivity, reduced conidiation, and overproduction of appressoria [49].

Adhesion of fungal propagules to the plant surface is the prerequisite to establish disease. We identified 8 homologs of Cellulose-Binding Elicitor Lectin (CBEL), a cell surface glycoprotein that plays a role in adhesion to host wall components [50], as well as a Class II hydrophobic protein which mediates contact and communication between the fungus and its environment [51]. $M$. phaseolina also has three transglutaminase-like proteins containing a 13-amino acid motif (Pep-13) that is able to stimulate the plant defense response. Presence of these cell surface proteins suggests that M. phaseolina produces PAMPs, which can be efficiently perceived by a wide range of plant species. Activation of the plant immune system results in the synthesis of antifungal peptides, inhibitors of cell wall degrading enzymes, and phytoalexins. At the same time, the fungus responds to surface inductive cues via a cAMP-dependent pathway in order to initiate the infection process and combat the plant defense response (e.g., production of salicylate-1monooxygenase).

Invasion begins with the emergence of a germ tube from the conidium, followed by appressorium formation. The developing appressorium swells as the cytoskeleton and Golgi vesicles accumulate in the tip. In bean rust pathogen Uromyces appendiculatus, the cytoskeleton and vesicles in the apex of the hypha are reorganized along the cell wall within 4 minutes of signal perception [52]. Enzymes for fungal cell wall synthesis (e.g., chitin synthase and $\beta$-1,3-glucan synthase) as well as cell wall degradation (e.g., cutinase and $\beta$-1,4-endoglucanase) are contained within different vesicles. M. phaseolina also synthesizes phytosphingosine and phytoceramide to protect the cell membrane from mechanical damage during penetration of the host cell. High turgor pressure is generated within the appressorium, allowing the penetration peg to break through the plant epidermis. Secretion of a variety of cell wall degrading enzymes and other toxins aid in the invasion of the host. These hyphae penetrate epidermal walls directly and subsequently colonize the tissue by intra- and intercellular growth (Figure 1c).

Regulation of these invasion processes involves both cAMP-dependent and MAP kinase pathways (Figure 5). Surface recognition and appressoria initiation is dependent on the adenylate cyclase MAC1 (MPH_00975). Early research revealed that deletion of the $M A C 1$ gene blocked appressorium formation in $M$. grisea [53]. The catalytic subunit of cAMP-dependent protein kinase A (MPH_07566 and MPH_00397) is also required for appressoria formation and penetration. Furthermore, the 


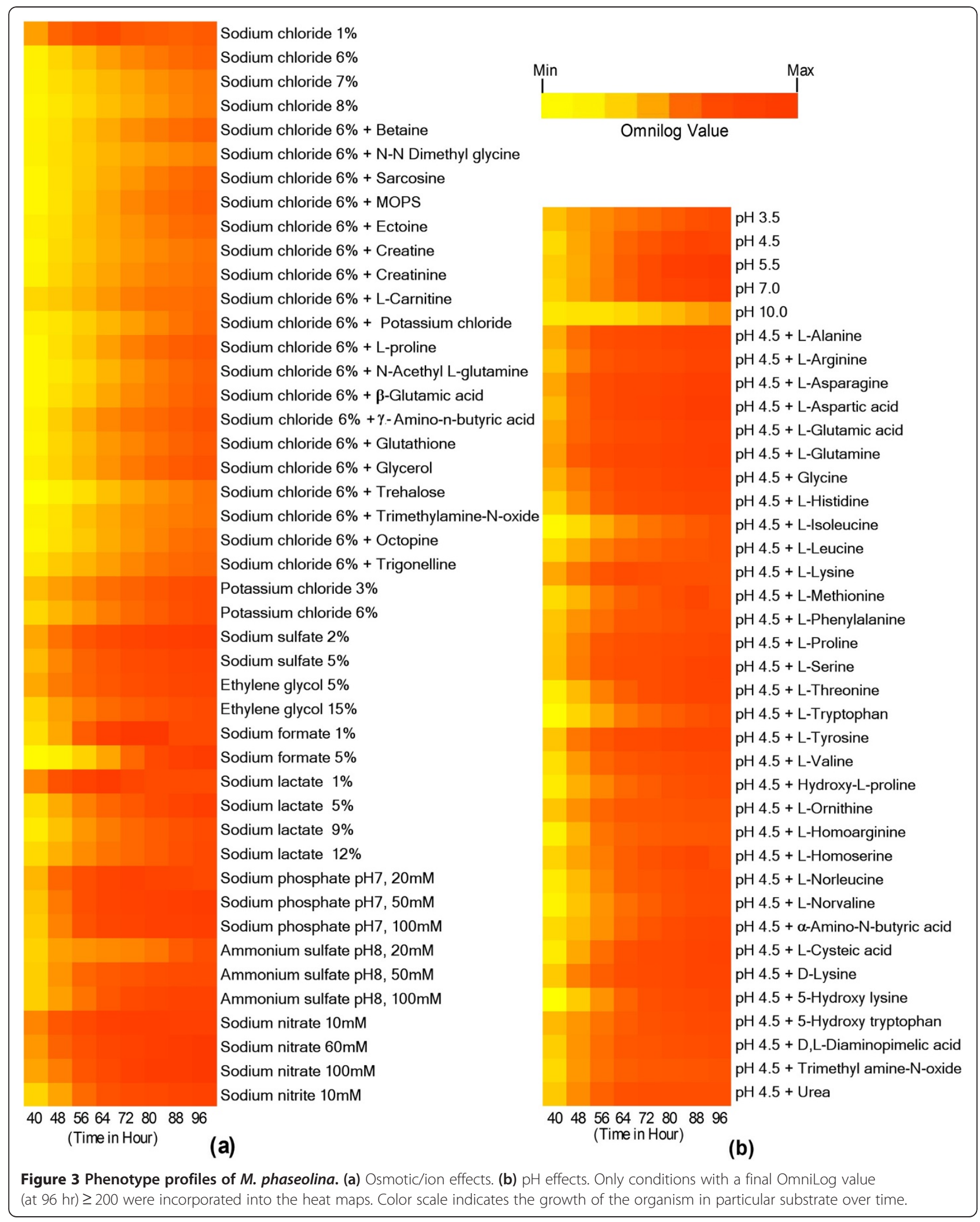




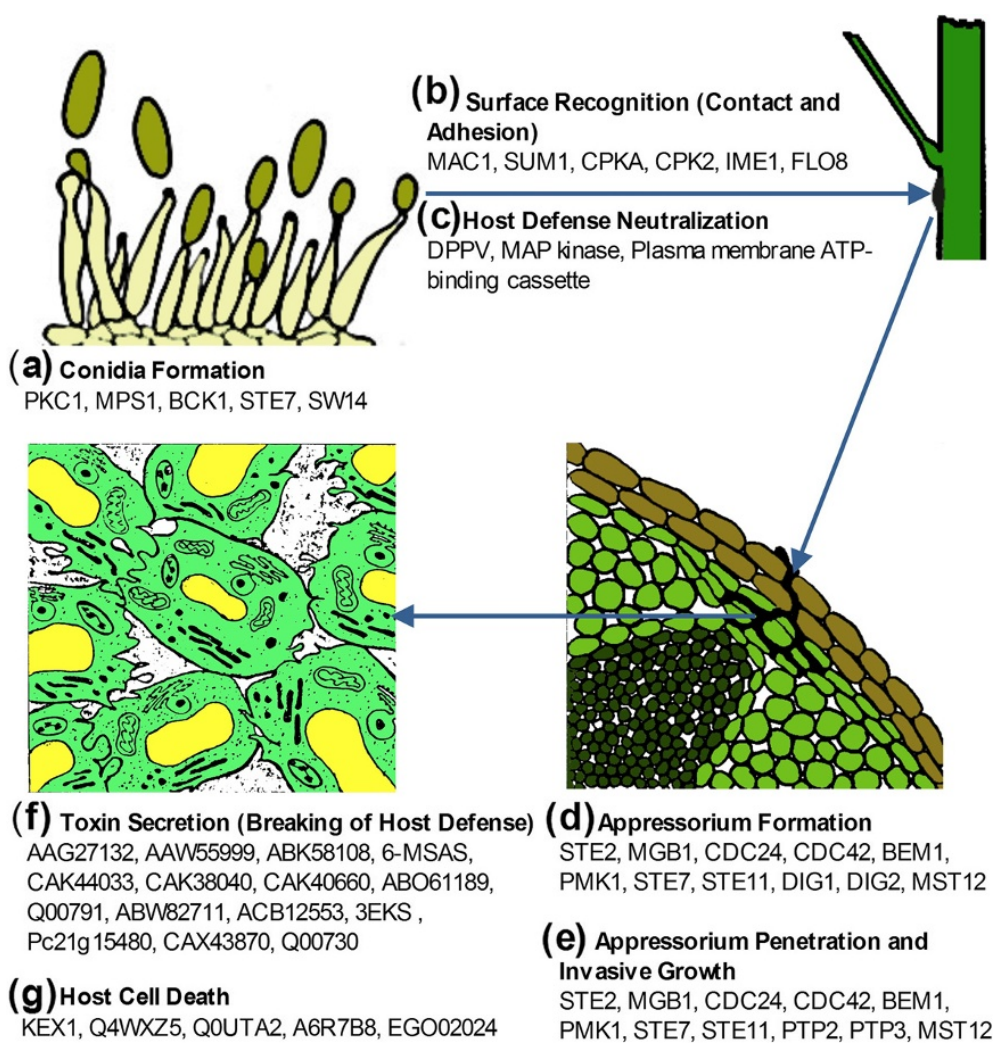

Figure 4 Pathogenic lifestyle and infection process of $\boldsymbol{M}$. phaseolina. (a) Conidia or sclerotia are released from the pathogen. (b) Conidia or sclerotia disperse during early rainy season and contact the host tissue with the aid of transglutaminase-like proteins and cellulose-binding elicitor lectin. (c) Pathogen neutralizes the initial host defense with salicylate-1-monooxygenase. (d) Conidia form appressorium under the control of the central regulator PMK1. (e) Penetration peg invades into the plant epidermis. (f) Inside the host, the pathogen releases an array of different toxins and cell wall degrading enzymes and finally breakdown the host defense. (g) Results in host cell death and self-establishment.

M. phaseolina genome contains heterotrimeric G-proteins (MPH_02326, MPH_07066, MPH_00770, MPH_05860 and MPH_09815), which could also contribute to the signaling pathways for pathogenesis. The later stage of plant penetration is regulated by the MAP kinase PMK1 (MPH_06596). A PMK1 mutant of $M$. grisea is unable to make appressoria in rice plants and is non-pathogenic. Therefore, $P M K 1$ is specifically involved in the regulation of appressorium formation in response to surface signals and is also necessary for invasive growth [54].

\section{Conclusions}

M. phaseolina is a soil-borne plant pathogenic fungus that infects major food, fiber, and oil crops, but it is also an opportunistic pathogen of humans [55]. Therefore, an understanding of the genetic basis underlying pathogenicity is crucial for controlling this pathogen.

Whole genome analysis showed that M. phaseolina is distinct from those of other known phytopathogenic fungi. We found $12 \%$ of the genes encoded by the genome have significant similarities with genes involved in pathogen-host interactions. M. phaseolina possesses a large repertoire of hydrolytic enzymes for degrading all major components of the plant cell wall and cuticle, including cellulose, hemicellulose, pectin, lignin, and cutin. The overall number of CAZymes is particularly high, primarily due to the abundance of GHs. Comparison with genomes of other phytopathogenic fungi reveals a distinct set of CEs in M. phaseolina, with significant expansion of families CE9 and CE10. CEs are considered as the first line of attack during host invasion and therefore play a key role in pathogenesis [56]. Extensive genetic diversity was also observed within complex gene families encoding peroxidases, oxidases, and cytochrome P450s. Interestingly, the genome has a considerable number of lignin peroxidases, extracellular Class II heme peroxidases, chloroperoxidases, and haloperoxidases compared with lignocellulose degrading fungus $P$. chrysosporium. The vast array of genes enables $M$. phaseolina to tackle nearly any type of cell wall composition it encounters, resulting in highly efficient penetration of different hosts and tissues.

We have identified differences in gene content among M. phaseolina and other plant pathogenic fungi. This is 


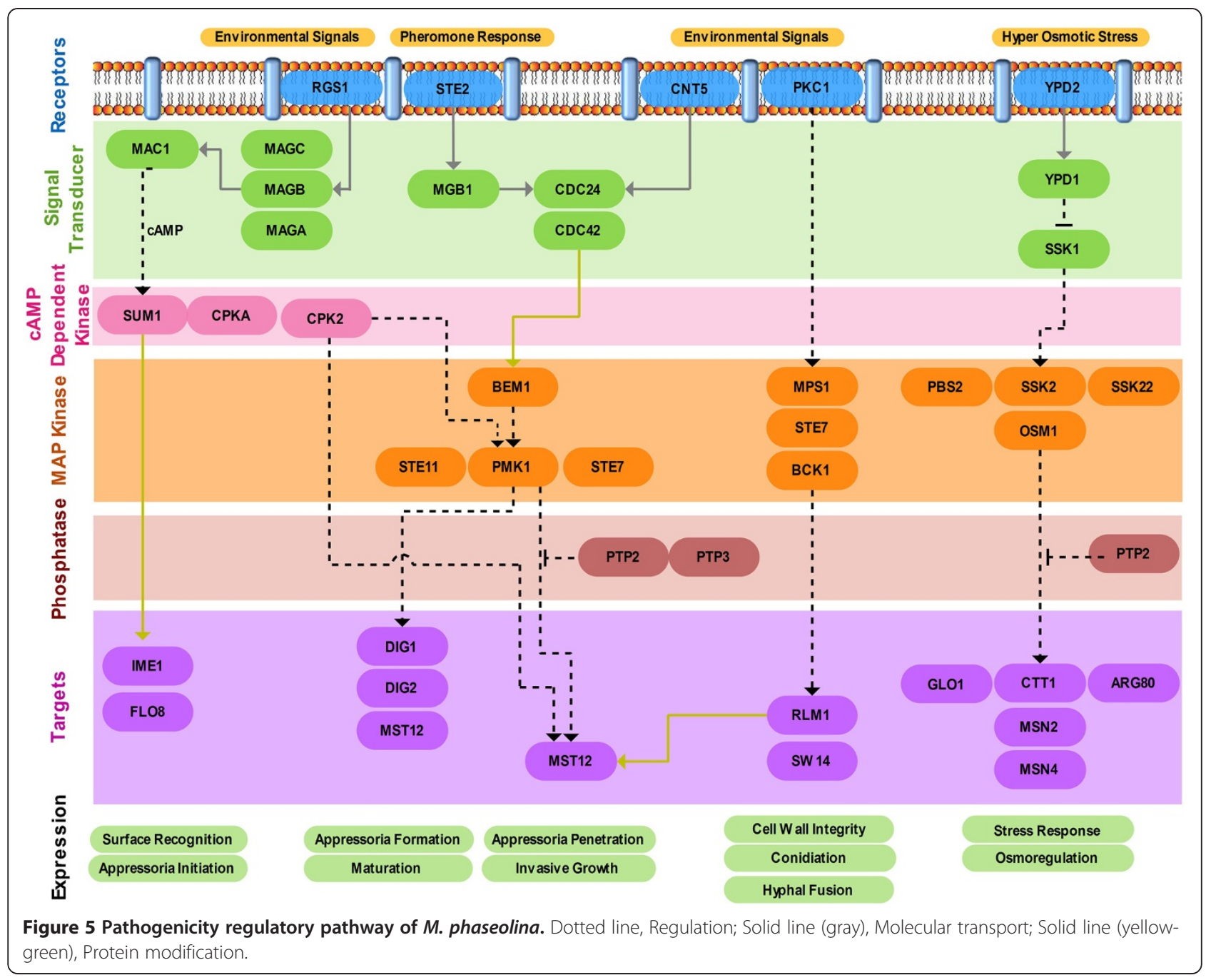

the first analysis of the genome of a plant pathogenic fungus that contains a large number of enzymes for the degradation of cell wall polysaccharides and lignocellulose. The M. phaseolina genome laid the foundation to elucidate its specialized mechanism to infect more than 500 plant hosts. Furthermore, it would decipher indepth understanding of pathogenesis to resistance strategies.

\section{Methods}

Strain, growth condition, and nucleic acid isolation

M. phaseolina strain MS6 was isolated from an infected jute plant at Bangladesh Jute Research Institute (BJRI), Dhaka. Strain MS6 is the most virulent among the 19 isolates so far isolated in BJRI. This strain has mycelium that is grey-white at the initial stage and turns dark green at the mature stage. It is coarse with feathery strand. The sclerotia are embedded in the strand. The fungus was cultured at $30^{\circ} \mathrm{C}$ in liquid potato dextrose medium. DNA and RNA were extracted as previously described $[57,58]$, respectively.

\section{Genome sequencing and assembly}

Whole-genome shotgun sequencing of the $M$. phaseolina MS6 strain was performed using the 454 and Illumina sequencing platforms. We generated a total of 6.92 Gb raw data, having 40.56 millions of raw reads. In the 454 sequencing strategy, both single-end (SE) and paired-end (PE) genomic libraries were constructed, of which $2.38 \mathrm{~Gb}$ of shotgun sequences provided $48.29 \mathrm{x}$ coverage and $1.57 \mathrm{~Gb}$ of $8 \mathrm{~kb}, 15 \mathrm{~kb}$, and $20 \mathrm{~kb} \mathrm{PE}$ sequences provided $31.95 \mathrm{x}$ coverage of the $M$. phaseolina genome. In the Illumina sequencing strategy, 2.97 $\mathrm{Gb}$ of PE libraries were generated, of which $1.73 \mathrm{~Gb}$ of 500 bp PE sequences provided $35.11 x$ coverage and 1.24 $\mathrm{Gb}$ of $3 \mathrm{~kb}$ mate-paired sequences provided $25.14 \mathrm{x}$ coverage of the M. phaseolina genome.

We produced a high quality assembly of the $M$. phaseolina genome using Newbler assembly program version 
2.5.3 (http://my454.com/products/analysis-software/index. asp). For both de novo assembly and reference mapping of the $M$. phaseolina genome, we only used raw data generated from 454 pyrosequencing. For de novo assembly, we fed the Newbler GS de novo assembler first with the shotgun sequences in one-step form and later with paired-end sequences incrementally in order to get better contigging and scaffolding. About $96.50 \%$ raw reads were assembled into 3,036 contigs and 94 scaffolds having $98.92 \%$ bases with Q40 plus bases. For reference mapping, we used Newbler GS reference mapper to map the raw sequence files onto the all contigs file generated that gave $98.89 \%$ reads and $99.11 \%$ bases mapped to the reference.

We also used Illumina PE sequences with GapCloser version 1.10, a tool from SOAP de novo (http://soap.genomics.org.cn/soapdenovo.html), in order to close the gaps inside the scaffolds that were generated from the Newbler scaffolding process. A total of 785 gaps were detected by GapCloser that cover $1.5 \mathrm{Mb}$ residues of which 197 gaps were completely filled up, leaving only $1.47 \%(0.73 \mathrm{Mb})$ gaps inside the 94 scaffolds.

We checked the relative completeness of the $M$. phaseolina MS6 draft assembly version 1.0 by performing core gene annotation using the CEGMA pipeline [59]. The resulting contigs as well as scaffolds from the $M$. phaseolina MS6 assembly were independently analyzed through this pipeline. In both cases we have found 245 (98.79\%) complete gene models out of 248 ultraconserved core eukaryotic genes (CEGs) present in the M. phaseolina genome.

This Whole Genome Shotgun project has been deposited at GenBank under the accession AHHD00000000. The version described in this paper is the first version, AHHD01000000.

\section{Genome annotation}

We used Program to Assemble Spliced Alignments (PASA), a eukaryotic genome annotation pipeline [60], to generate potential training gene sets that were used to train other $a b$ initio gene prediction software like Augustus v. 2.5.5 [61] and Glimmer HMM v. 3.0.1 [62] for predicting $M$. phaseolina genes.

A total of 13,481 gene assemblies under 11,414 gene clusters predicted by PASA, along with cDNA of $M$. phaseolina and other 4 closely related species (Aspergillus nidulans, M. grisea, P. marneffei, and S. cerevisiae) were used for this training purpose. Augustus and Glimmer independently predicted 12,231 and 11,432 ORFs, respectively, which were then subjected to correct gene structure annotation by EVidenceModeler (EVM) [63]. EVM, when combined with PASA, yields a comprehensive, configurable annotation system that predicts protein-coding genes and alternatively spliced isoforms.
We also used Analysis and Annotation Tool (AAT) [64] as a pipeline for transcript and protein alignments. To align the $M$. phaseolina genome independently, we used cDNA of its own with cDNA of other 4 related fungal species (described earlier) and fungal protein databases downloaded from Fungal Genome Research (http://fungalgenome.org/data/PEP/). These two along with PASA transcript alignments were used as transcript and protein evidences for EVM. Finally, a total of 14,249 $a b$ initios were predicted of which 11,975 were corrected gene structures from EVM along with 2,274 genes from Augustus and Glimmer underlying the intergenic region of EVM predictions.

The $a b$ initios were then subjected to InterProScan [65] and nr BLAST (threshold value of $E<10^{-5}$ ) [66] for searching functional domains and homologies. Results revealed a total of 10,250 genes with either potential domains or homologies with other fungal proteins and 3,999 novel genes out of 14,249 predicted protein coding genes of $M$. phaseolina.

Transfer RNA-coding regions were searched using tRNAscan-SE [67] and rRNA was searched using RNAmmer [68]. Repetitive elements were predicted by using RepeatMasker (http://www.repeatmasker.org/) and Putative Transposon elements were identified by Transposon-PSI (http://transposonpsi.sourceforge.net), a program that performs tBLASTn searches using a set of position specific scoring matrices (PSSMs) specific for different TE families.

The genomes of $M$. phaseolina and $F$. oxysporum were compared using MUMmer [69] tools to identify regions of synteny, with Aspergillus fumigatus used as a reference genome. For visualizing multiple genome comparisons, SyntenyMiner (http://syntenyminer.sourceforge. net/) was also used to visualize orthologous gene clusters among the organisms.

To identify proteins involved in carbohydrate metabolism, we used the Carbohydrate Active Enzymes (CAZy) database (http://www.cazy.org/). All CAZy related GenBank accession numbers were first downloaded from the CAZy website and then sequences were downloaded from NCBI using a custom python script. These sequences were searched by RPS-BLAST against the Pfam database to reveal protein domain architectures and compared against the Pfam domains identified in $M$. phaseolina proteins. The sequences were also compared by BLASTp against all $M$. phaseolina proteins to confirm the Pfam database matches.

Putative secondary metabolites (PKS and NRPS) were identified by using antiSMASH [70]. Pathogenicity and virulence associated genes were identified using the PHI-base database (http://www.phibase.org/), a database that catalogs experimentally verified pathogenicity, virulence, and effector genes from fungal, Oomycete, and 
bacterial pathogens which infect animal, plant, fungal and insect hosts. Briefly, all sequences were first downloaded from the PHI-base database and then compared by BLASTp against all $M$. phaseolina proteins to confirm the presence of homologous genes in the M. phaseolina genome.

The in silico predictions were manually curated and tested experimentally with several larger gene families such as CAZymes and lignin degrading protein coding genes by PCR.

\section{Construction of phylogenetic tree}

Orthologous relationships were determined for a 14-way clustering from the complete genomes of the 14 fungal taxa: Aspergillus nidulans, Fusarium oxysporum, Penicillium chrysogenum, Grosmannia clavigera, Magnaporthe grisea, Podospora anserina, M. phaseolina, Botryosphaeria dothidea, Laccaria bicolor, Phanerochaete chrysosporium, Postia placenta, Yarrowia lipolytica, Saccharomyces cerevisiae, and Trichoderma reesei. All predicted protein sequences for the genomes of these fungi were searched against each other using BLASTp and clustered into orthologous groups using MCL-10-201. Single-copy orthologs were identified as the clusters with exactly one member per species. Phylogenetic relationships were determined from these single-copy orthologs and were aligned with MAFFT [71]. Alignments were pruned with Gblocks [72].

The evolutionary history was inferred by using the Maximum Likelihood method based on the JTT matrixbased model [73] and bootstrap value was 1,000. Evolutionary analyses were conducted in MEGA5 [74].

\section{Metabolic pathway reconstruction}

The Yeast-5 Pathway Studio database (Ariadne Genomics) contains molecular interactions extracted by MedScan natural processing technology for all fungal species from over 1,000,000 Pubmed abstracts annotated with Medical Subject Headings (MeSH) term "Yeast OR Fungi" and from more than 100,000 full-length open access articles. Proteins in the Yeast-5 database are annotated with Entrez Gene and GenBank identifiers from six fungal genomes: S. cerevisiae, Schizosaccharomyces pombe, Cryptococcus neoformans var. neoformans JEC21, A. fumigatus Af293, A. nidulans FGSC A4, and Aspergillus niger CBS 513.88. To facilitate analysis of the M. phaseolina genome, we have added to the Yeast- 5 database annotated proteins from recently sequenced genomes for Ustilago maydis 52 [75], Metarhizium anisopliae ARSEF 23, and Metarhizium acridum CQMa 102 [76].

The Yeast- 5 database contains a collection of 303 metabolic pathways copied from MetaCyc. Pathways are represented as a collection of complex database entities called functional classes (enzymes) and a set of corresponding Chemical reactions. Every functional class in the database can contain an unlimited number of protein members performing corresponding enzymatic activity. Usually a set of members includes paralogs of catalytic and regulatory subunits necessary to perform enzymatic activity. The original Yeast- 5 database has 444 functional classes with members out of a total of 769 pathways. We augmented the Yeast-5 database with an additional 168 metabolic pathways from RiceCyc and PoplarCyc to increase the pool of candidate enzymatic reactions for metabolic reconstruction of M. phaseolina.

The database of $M$. phaseolina interologs (predicted interactions) and reconstructed pathways was created by annotating proteins in the Yeast-5 database with $M$. phaseolina ortholog identifiers. Orthologs for M. phaseolina proteins in other fungal organisms were calculated using the best reciprocal hit method from full length protein sequence similarities calculated from BLAST alignments as described previously [77]. First, orthologs were calculated between M. phaseolina and each of the nine fungal genomes supported in the Yeast- 5 database. The best ortholog was then chosen for each M. phaseolina protein among the nine possible ortholog pairs. All interactions extracted for $M$. phaseolina orthologs were exported from the Yeast-5 database along with pathways containing M. phaseolina orthologs. M. phaseolina interologs and predicted pathways were imported into a new Pathway Studio database for manual pathway reconstruction and genome analysis. Pathways that contained at least one functional class with no $M$. phaseolina orthologs were manually curated to achieve one of the following three outcomes: a) close the gap by finding members in the $M$. phaseolina genome and adding them to empty functional classes, b) dismiss entire pathway if gap cannot be closed, or c) remove enzymatic step if empty functional class represents redundant path in the pathway.

To identify paralog families in the M. phaseolina genome, we used BLASTP to calculate all possible protein homologs in the $M$. phaseolina genome and then selected only homologs that have $30 \%$ shared amino acid similarity calculated as the average sequence similarity between two homologs. Paralog pairs were imported into the M. phaseolina database as a new type of interaction called "Paralog". Protein functional families were identified as clusters in the global Paralog network using the direct force layout algorithm. To assign biological function to each Paralog cluster we found Gene Ontology groups enriched by the proteins in the cluster or simply inspected available functional annotation for proteins in the cluster.

\section{Phenotype microarray analysis}

Phenotype microarray (PM) is a high-throughput technique for screening the response of an organism against 
various substrates. M. phaseolina was evaluated using panels PM1 to PM10 (Biolog Inc.). The PM plates are denoted as PM1 and PM2A MicroPlates for Carbon sources; PM3B MicroPlate for Nitrogen sources; PM4A MicroPlate for Phosphorus and Sulfur sources; PM5 MicroPlate for Nutrient supplements; PM6, PM7, and PM8 MicroPlates for Peptide nitrogen sources; PM9 MicroPlate for Osmolytes; and PM10 MicroPlate for $\mathrm{pH}$. There are 96 wells in each plate, so the substrate utilization patterns by the fungus were evaluated against a total of 960 substrates including 9 negative and 4 positive controls (see Additional file 3 for list of substrates).

M. phaseolina was grown on potato dextrose agar (PDA) at $30^{\circ} \mathrm{C}$ for $72 \mathrm{hr}$. Active hyphae was inoculated into $30 \mathrm{ml}$ of liquid potato dextrose medium and incubated at $30^{\circ} \mathrm{C}$ for $60 \mathrm{hr}$. The mycelia from the liquid culture $(\sim 2 \mathrm{~g})$ were washed with physiological buffer solution (10 mM sodium phosphate, $\mathrm{pH} 7.0$, filter sterilized) at least 7 times to remove nutrient contamination. After washing, the mycelia were aliquoted into two $1.5 \mathrm{ml}$ microcentrifuge tubes and macerated by a pellet pestle motor for 15 minutes. One $\mathrm{ml}$ of filamentous fungi inoculating fluid (FF-IF, Biolog) was added into each tube. The solution was transferred into a $15 \mathrm{ml}$ falcon tube and $6 \mathrm{ml}$ of FF-IF was added. The macerated mycelia were centrifuged at $3500 \mathrm{rpm}$ for 5 minutes and the supernatant was discarded. Six to $8 \mathrm{ml}$ of FF-IF was added to the tube and let stand for at least 40 minutes to settle down the bigger mycelial clumps. Approximately $2 \mathrm{ml}$ from the clear upper portion was harvested for measuring the transmittance at $\mathrm{OD}_{590 \mathrm{~nm}}$. The transmittance was adjusted to $62 \%$ for usable concentration of inoculums.

The inoculum suspensions along with different stock solutions were prepared as per the protocol standardized by Biolog ("PM Procedures for Filamentous Fungi", 25Aug-07). All the wells of PM 1-10 were inoculated with $100 \mu \mathrm{l}$ of the inoculum suspensions and incubated in the OmniLog machine at $30^{\circ} \mathrm{C}$ for $96 \mathrm{hr}$. The instrument was programmed for recording data from each well in 15 minute intervals. After completion of incubation, the recorded data were extracted and analyzed using TIBCO Spotfire v23.0.0.320. The experiment was replicated three times.

It was observed that there was almost no growth in all the plates up to $40 \mathrm{hr}$ of incubation. We therefore considered the $40 \mathrm{hr}$ incubation readings as the baseline in our analysis. The data for each 8 hrs from three replications were averaged for analysis. Based on the $96 \mathrm{hr}$ reading, all the figures (Figure 3; Additional file 2: Figures S6-S11) were constructed using OmniLog value $\geq 200$.

\section{Verification of lignin degradation}

We measured the ability of $M$. phaseolina to degrade lignin on modified Boyd and Kohlmeyer (B\&K) agar medium containing $4 \mathrm{mM}$ guaiacol along with $0.001 \%$ azure $\mathrm{B}$ dye [78]. The medium was inoculated with this fungus and incubated at $30^{\circ} \mathrm{C}$ in the dark. After 4 days of incubation, a halo of intense brownish white color was formed under and around the fungal colony, and the azure B dye turned from blue to white (Additional file 2: Figure S5). The growth of intense brownish white color fungal colony indicates a positive reaction resulting from guaiacol oxidation [79]. The disappearance of the blue colored medium is also evidence of peroxidase production (Additional file 2: Figure S5). The discoloration of azure B dye has been positively correlated with the production of lignin peroxidase and Mn dependent peroxidase, but it does not indicate the presence of laccase [80].

\section{Additional files}

Additional file 1: Supplemental Table S1 to Table S8. Table S1 provides the raw data generation statistics. Table $\mathbf{S} 2$ provides the assembly statistics of $M$. phaseolina genome. Table S3 provides the transcriptome assembly statistics. Table $\$ 4$ lists the InterPro codes corresponding to the protein families in Table 2. Table S5 lists the virulence associated genes in M. phaseolina. Table S6 lists the transporter families in M. phaseolina. Table S7 details the M. phaseolina gene models corresponding to Figure 4. Table S8 details the $M$. phaseolina gene models corresponding to Figure 5.

Additional file 2: Supplemental Figure S1 to Figure S11, supporting data analyses. Figure S1 indicates the number of unique and shared genes between M. phaseolina and F. oxysporum. Figure S2 shows the paralog network clusters of M. phaseolina. Figure S3 indicates the distribution of transposable elements over the genome. Figure S4 indicates the distribution of CAZymes against the 15 largest supercontigs of $M$. phaseolina. Figure S5 shows the positive guaiacol oxidation by $M$. phaseolina after 4 days of inoculation. Figures S6 to S11 show the PM profiles for various substrates.

Additional file 3: Supplemental methods. This file provides the full list of substrates assayed in the PM experiments.

\section{Abbreviations}

AAT: Analysis and Annotation Tool; ABC: ATP-binding cassette; APC: Amino acid-polyamine-organocation; CAZy: Carbohydrate active enzyme;

CBEL: Cellulose-binding elicitor lectin; CBM: Carbohydrate binding module; CE: Carbohydrate esterase; CEG: Core eukaryotic gene; DMAT: Dimethylallyl tryptophan synthase; EST: Expressed sequence tag; EVM: EVidenceModeler; GH: Glycoside hydrolase; GPCR: G-protein coupled receptor;

GT: Glycosyltransferase; HYBRID: Hybrid PKS-NRPS enzyme; MeSH: Medical Subject Heading; MFS: Major facilitator superfamily; NCBI: National Center for Biotechnology Information; NRPS: Non-ribosomal peptide synthetase; ORF: Open reading frame; PAMP: Pathogen-associated molecular pattern; PASA: Program to Assemble Spliced Alignments; PDA: Potato dextrose agar; PE: Paired-end; PHI: Pathogen-host interaction; PKS: Polyketide synthase; PL: Polysaccharide lyase; PM: Phenotype microarray; PSSMs: Position specific scoring matrices; RIP: Repeat-induced point mutation.

\section{Competing interests}

The authors declare that they have no competing interests.

\section{Authors' contributions}

MA designed the study; MSI, MSH, MMI, EME, AH, QMMH, MZH, BA, SR, MSR, MMA, SH, and XW performed the experiments; MSI, MSH, MMI, EME, AH, QMMH, MZH, BA, SR, MSR, MMA, and MA analyzed the data; MSI, MSH, JAS, and MA wrote the manuscript. All authors read and approved the final manuscript. 


\section{Acknowledgments}

We thank Rasel Ahmed, Md. Amzad Hossain, and Md. Mursalin Khan for their initial help and Anton Yuryev from Ariadne Genomics, Elsevier Company for initial pathway reconstruction. We also thank Project Director, Basic and Applied Research on Jute project and Director General, Bangladesh Jute Research Institute Dr. Md. Kamal Uddin for his continuous support for the program. This research was funded by the Government of Bangladesh.

\section{Author details}

'Basic and Applied Research on Jute Project, Bangladesh Jute Research Institute, Manik Mia Avenue, Dhaka 1207, Bangladesh. ${ }^{2}$ Advanced Studies in Genomics, Proteomics and Bioinformatics, University of Hawaii, 2565 McCarthy Mall, Keller 319, Honolulu, Hawaii 96822, USA. ${ }^{3}$ Centre for Chemical Biology, Universiti Sains Malaysia, Penang 11800, Malaysia.

Received: 17 January 2012 Accepted: 13 September 2012 Published: 19 September 2012

\section{References}

1. Wyllie TD: Charcoal rot of soybean-current status. In Soybean Diseases of the North Central Region. Edited by Wyllie TD, Scott DH. St. Paul: APS; 1988:106-113.

2. Su G, Suh SO, Schneider RW, Russin JS: Host specialization in the charcoal rot fungus, Macrophomina phaseolina. Phytopathology 2001, 91:120-126.

3. Mayek-Pérez N, López-Castañeda C, López-Salinas E, Cumpián-Gutiérrez J, Acosta-Gallegos JA: Macrophomina phaseolina resistance in common bean under field conditions in Mexico. Agrociencia 2001, 35:649-661.

4. Raguchander T, Samiyappan R, Arjunan G: Biocontrol of Macrophomina root rot of mungbean. Indian Phytopathol 1993, 46:379-382.

5. De BK, Chattopadhya SB: Effect of potash on stem rot diseases of jute caused by Macrophomicna phaseolina. J Mycopathol Res 1992, 30:51-55.

6. Aly AA, Abdel-Sattar MA, Omar MR, Abd-Elsalam KA: Differential antagonism of Trichoderma sp. against Macrophomina phaseolina. J Plant Protection Res 2007, 47:91-102.

7. Khan SK: M. phaseolina as causal agent for charcoal rot of sunflower. Mycopath 2007, 5:111-118.

8. Dinakaran D, Mohammed N: Identification of resistant sources to root rot of sesame caused by M. phaseolina (Tassi.) Goid. Sesame and Safflower Newsletter 2001, 16:68-71.

9. Wyllie TD: Charcoal rot. In Compendium of Soybean Diseases. 3rd edition. Edited by Sinclair JB, Backman PA. St. Paul: APS; 1993:30-33.

10. Sandhu A, Singh RD, Sandhu A: Factors influencing susceptibility of cowpea to M. phaseolina. J Mycol Plant Pathol 1999, 29:421-424.

11. Short GE, Wyllie TD, Bristow PR: Survival of M. phaseolina in soil and residue of soybeans. Phytopathology 1980, 70:13-17.

12. Mahmoud A, Budak H: First report of charcoal rot caused by M. phaseolina in sunflower in Turkey. Plant Dis 2011, 95:223.

13. Avilés M, Castillo S, Bascon J, Zea-Bonilla T, Martín-Sánchez PM, PérezJiménez RM: First report of $M$. phaseolina causing crown and root rot of strawberry in Spain. Plant Pathol 2008, 57:382.

14. Khangura R, Aberra M: First reports of charcoal rot on canola caused by M. phaseolina in Western Australia. Plant Dis 2009, 93:666

15. Gray FA, Kolp BJ, Mohamed MA: A disease survey of crops grown in the Bay Region of Somalia, East Africa. FAO Plant Prot Bull 1990, 38:39-47.

16. Diourte M, Starr JL, Jeger MJ, Stack JP, Rosenow DT: Charcoal rot (Macrophomina phaseolina) resistance and the effects of water stress on disease development in sorghum. Plant Pathol 1995, 144:196-202.

17. Wrather JA, Anderson TR, Arsyad DM, Tan Y, Ploper LD, Porta-Puglia A, Ram $\mathrm{HH}$, Yorinori JT: Soybean disease loss estimates for the top 10 soybean producing countries in 1998. Can J Plant Pathol 2001, 23:115-121.

18. Wrather JA, Koenning SR, Anderson TR: Effect of diseases on soybean yields in the United States and Ontario (1999-2002). Online. Plant Health Progress 2003, doi:10.1094/PHP-2003-0325-01-RV.

19. Ammon V, Wyllie TD, Brown MF: An ultrastructural investigation of pathological alterations induced by M. phaseolina (Tassi) Goid. in seedlings of soybean, Glycine max (L.) Merril. Physiol. Plant Pathol 1974 $4: 1-4$.

20. Cuomo CA, Güldener U, Xu JR, Trail F, Turgeon BG, Di Pietro A, Walton JD, Ma L, Baker SE, Rep M, Adam G, Antoniw J, Baldwin T, Calvo S, Chang YL, Decaprio D, Gale LR, Gnerre S, Goswami RS, Hammond-Kosack K, Harris LJ, Hilburn K, Kennell JC, Kroken S, Magnuson JK, Mannhaupt G, Mauceli E,
Mewes HW, Mitterbauer R, Muehlbauer G, et al: The Fusarium graminearum genome reveals a link between localized polymorphism and pathogen specialization. Science 2007, 317:1400-1402.

21. Lowe RGT, Howlett BJ: Indifferent, affectionate, or deceitful: Lifestyles and secretomes of fungi. PLoS Pathog 2012, 8:e1002515. doi:10.1371/journal. ppat.1002515.

22. Gough J, Karplus K, Hughey R, Chothia C: Assignment of homology to genome sequences using a library of hidden markov models that represent all proteins of known structure. J Mol Biol 2001, 313:903-919.

23. Kang S, Lebrun MH, Farrall L, Valent B: Gain of virulence caused by insertion of a Pot3 transposon in a Magnaporthe grisea avirulence gene. Mol Plant Microbe Interact 2001, 14:671-674.

24. Hane JK, Oliver RP: RIPCAL: a tool for alignment-based analysis of repeatinduced point mutations in fungal genomic sequences. BMC Bioinforma 2008, 9:478.

25. Knogge W: Fungal Infection of Plants. Plant Cell 1996, 8:1711-1722.

26. Kaur S, Dhillon GS, Brar SK, Chauhan VB: Carbohydrate degrading enzyme production by plant pathogenic mycelia and microsclerotia isolates of Macrophomina phaseolina through koji fermentation. Ind Crop Prod 2012, 36:140-148.

27. Martinez D, Larrondo LF, Putnam N, Gelpke MD, Huang K, Chapman J, Helfenbein KG, Ramaiya P, Detter JC, Larimer F, Coutinho PM, Henrissat B, Berka R, Cullen D, Rokhsar D: Genome sequence of the lignocellulose degrading fungus Phanerochaete chrysosporium strain RP78. Nat Biotechnol 2004, 22:695-700.

28. Winnenburg R, Urban M, Beacham A, Baldwin TK, Holland S, Lindeberg M, Hansen H, Rawlings C, Hammond-Kosack KE, Kohler J: PHI-base update: additions to the pathogen host interaction database. Nucleic Acids Res 2008, 36:572-576.

29. Morschhauser J: Regulation of multidrug resistance in pathogenic fungi. Fungal Genet Biol 2010, 47:94-106.

30. Beck J, Ripka S, Siegner A, Schiltz E, Schweizer E: The multifunctional 6methylsalicylic acid synthase gene of Penicillium patulum. Its gene structure relative to that of other polyketide synthases. Eur J Biochem 1990, 192:487-498

31. Kulkarni RD, Thon MR, Pan H, Dean RA: Novel G-protein-coupled receptorlike proteins in the plant pathogenic fungus Magnaporthe grisea. Genome Biol 2005, 6:R24

32. Solomon PS, Tan KC, Sanchez P, Cooper RM, Oliver RP: The disruption of a Galpha subunit sheds new light on the pathogenicity of Stagonospora nodorum on wheat. Mol Plant Microbe Interact 2004, 17:456-466.

33. Li L, Wright SJ, Krystofova S, Park G, Borkovich KA: Heterotrimeric G protein signaling in filamentous fungi. Annu Rev Microbiol 2007, 61:423-452.

34. Fang W, St Leger RJ: Mrt, a gene unique to fungi, encodes an oligosaccharide transporter and facilitates rhizosphere competency in Metarhizium robertsii. Plant Physiol 2010, 154:1549-1557.

35. Nelson DR: Cytochrome P450 and the individuality of species. Arch Biochem Biophys 1999, 369:1-10.

36. Maloney AP, VanEtten HD: A gene from the fungal plant pathogen Nectria haematococca that encodes the phytoalexin detoxifying enzyme pisatin demethylase defines a new cytochrome P450 family. Mol Gen Genet 1994, 243:506-514.

37. Suvarna K, Bartiss A, Wong B: Mannitol-1-phosphate dehydrogenase from Cryptococcus neoformans is a zinc-containing long-chain alcohol/polyol dehydrogenase. Microbiology 2000, 146:2705-2713.

38. Duke SO, Vaughn KC: Lack of involvement of polyphenol oxidase in ortho-hydroxylation of phenolic compounds in mung bean seedlings. Physiol Plant 1982, 54:381-385.

39. Okoro1 IO, Osagie A, Asibor EO: Antioxidant and antimicrobial activities of polyphenols from ethnomedicinal plants of Nigeria. African J Biotechnol 2010, 9:2989-2993.

40. John P, Morrissey, Osbourn AE: Fungal resistance to plant antibiotics as a mechanism of pathogenesis. Microbiol Mol Biol Rev 1999, 63:708-724.

41. Wolpert TJ, Dunkle LD, Ciuffetti LM: Host-selective toxins and avirulence determinants: what's in a name? Annu Rev Phytopathol 2002, 40:251-285.

42. Oide S, Moeder W, Krasnoff S, Gibson D, Haas H, Yoshioka K, Turgeon BG: NPS6, encoding a nonribosomal peptide synthetase involved in siderophore-mediated iron metabolism, is a conserved virulence determinant of plant pathogenic ascomycetes. Plant Cell 2006, 18:2836-2853. 
43. Panaccione DG, Scott-Craig JS, Pocard JA, Walton JD: A cyclic peptide synthetase gene required for pathogenicity of the fungus Cochliobolus carbonum on maize. Proc Natl Acad Sci USA 1992, 89:6590-6594.

44. Böhnert HU, Fudal I, Dioh W, Tharreau D, Notteghem JL, Lebrun MH: A putative polyketide synthase/peptide synthetase from Magnaporthe grisea signals pathogen attack to resistant rice. Plant Cell 2004, 16:2499-2513.

45. Gunde-Cimernam N, Zalar P, Hoog SD, Plemenitas A: Hypersaline waters in salterns - natural ecological niches for halophilic black yeasts. FEMS Microbiol Ecol 2000, 32:235-240.

46. You MP, Colmer TD, Barbetti MJ: Salinity drives host reaction in Phaseolus vulgaris (common bean) to Macrophomina phaseolina. Funct Plant Biol 2011, 38:984-992.

47. Herranz S, Rodríguez JM, Bussink HJ, Sánchez-Ferrero JC, Arst HN Jr, Peñalva $\mathrm{MA}$, Vincent $\mathrm{O}$ : Arrestin-related proteins mediate $\mathrm{pH}$ signaling in fungi. Proc Natl Acad Sci USA 2005, 102:12141-12146.

48. Duran R, Cary JW, Calvo AM: Role of the osmotic stress regulatory pathway in morphogenesis and secondary metabolism in filamentous fungi. Toxins 2010, 2:367-381.

49. Dixon KP, Xu JR, Smirnoff N, Talbot NJ: Independent signaling pathways regulate cellular turgor during hyperosmotic stress and appressorium mediated plant infection by the rice blast fungus Magnaporthe grisea. Plant Cell 1999, 11:2045-2058

50. Gaulin E, Jauneau A, Villalba F, Rickauer M, Esquerré-Tugayé MT, Bottin A: The CBEL glycoprotein of Phytophthora parasitica var. nicotianae is involved in cell wall deposition and adhesion to cellulosic substrates. J Cell Sci 2002, 115:4565-4575.

51. Whiteford JR, Spanu PD: The hydrophobin HCf-1 of Cladosporium fulvum is required for efficient water-mediated dispersal of conidia. Fungal Genet Biol 2001, 32:159-168.

52. Kwon $\mathrm{YH}$, Hoch HC, Aist JR: Initiation of appressorium formation in Uromyces appendiculatus: organization of the apex and the responses involving microtubules and apical vesicles. Can J Bot 1991, 69:2560-2573.

53. Choi W, Dean RA: The adenylate cyclase gene MAC1 of Magnaporthe grisea controls appressorium formation and other aspects of growth and development. Plant Cell 1997, 9:1973-1983.

54. $\mathrm{Xu} \mathrm{J-R,} \mathrm{Hamer} \mathrm{JE:} \mathrm{MAP} \mathrm{kinase} \mathrm{and} \mathrm{CAMP} \mathrm{signaling} \mathrm{regulate} \mathrm{infection}$ structure formation and pathogenic growth in the rice blast fungus Magnaporthe grisea. Genes Dev 1996, 10:2696-706.

55. Tan DHS, Sigler L, Gibas CFC, Fong IW: Disseminated fungal infection in a renal transplant recipient involving $M$. phaseolina and Scytalidium dimidiatum: case report and review of taxonomic changes among medically important members of the Botryosphaeriaceae. Med Mycol 2008, 46:285-292.

56. Ospina-Giraldo MD, Griffith JG, Laird EW, Mingora C: The CAZyome of Phytophthora spp.: A comprehensive analysis of the gene complement coding for carbohydrate-active enzymes in species of the genus Phytophthora. BMC Genomics 2010, 11:525-540.

57. Benčina $M$, Jakopič $M$, Friedrich J: High-molecular-weight genomic DNA isolation from Doratomyces microsporus and synthesis of a genomic DNA library. Acta Chim Slov 2007, 54:893-899.

58. Li Y, Wang W, Du X, Yuan Q: An improved RNA isolation method for filamentous fungus Blakeslea trispora rich in polysaccharides. Appl Biochem Biotechnol 2010, 160:322-327.

59. Parra G, Bradnam K, Korf I: CEGMA: a pipeline to accurately annotate core genes in eukaryotic genomes. Bioinformatics 2007, 23:1061-1067.

60. Haas BJ, Delcher AL, Mount SM, Wortman JR, Smith RK Jr, Hannick LI, Maiti R, Ronning CM, Rusch DB, Town CD, Salzberg SL, White O: Improving the Arabidopsis genome annotation using maximal transcript alignment assemblies. Nucleic Acids Res 2003, 31:5654-5666.

61. Stanke M, Waack S: Gene prediction with a hidden Markov model and a new intron submodel. Bioinformatics 2003, 19:215-225.

62. Majoros WH, Pertea M, Salzberg SL: TigrScan and GlimmerHMM: two open source $a b$ initio eukaryotic gene-finders. Bioinformatics 2004, 20:2878-2879

63. Haas BJ, Salzberg SL, Zhu W, Pertea M, Allen JE, Orvis J, White O, Buell CR, Wortman JR: Automated eukaryotic gene structure annotation using EVidenceModeler and the Program to Assemble Spliced Alignments. Genome Biol 2008, 9:R7.

64. Huang $X$, Adams MD, Zhou H, Kerlavage AR: A tool for analyzing and annotating genomic sequences. Genomics 1997, 46:37-45.
65. Zdobnov EM, Apweiler R: InterProScan - an integration platform for the signature-recognition methods in InterPro. Bioinformatics 2001, 17:847-848

66. Altschul SF, Gish W, Miller W, Myers EW, Lipman DJ: Basic local alignment search tool. J Mol Biol 1990, 215:403-410.

67. Lowe TM, Eddy SR: tRNAscan-SE: a program for improved detection of transfer RNA genes in genomic sequence. Nucleic Acids Res 1997, 25:955-964.

68. Lagesen K, Hallin PF, Rødland E, Stærfeldt HH, Rognes T, Ussery DW: RNAmmer: consistent and rapid annotation of ribosomal RNA genes. Nucleic Acids Res 2007, 35:3100-3108.

69. Kurtz S, Phillippy A, Delcher AL, Smoot M, Shumway M, Antonescu C, Salzberg SL: Versatile and open software for comparing large genomes. Genome Biol 2004, 5:R12.

70. Medema MH, Blin $K$, Cimermanci $P$, de Jager $V$, Zakrzewski $P$, Fischbach MA, Weber T, Takano E, Breitling R: antiSMASH: rapid identification, annotation and analysis of secondary metabolite biosynthesis gene clusters in bacterial and fungal genome sequences. Nucleic Acid Res 2011, 39:1-8.

71. Katoh $\mathrm{K}$, Toh $\mathrm{H}$ : Improved accuracy of multiple ncRNA alignment by incorporating structural information into a MAFFT-based framework. BMC Bioinforma 2008, 9:212.

72. Castresana J: Selection of conserved blocks from multiple alignments for their use in phylogenetic analysis. Mol Biol Evol 2000, 17:540-552.

73. Jones DT, Taylor WR, Thornton JM: The rapid generation of mutation data matrices from protein sequences. Comput Appl Biosci 1992, 8:275-282.

74. Tamura K, Peterson D, Peterson N, Stecher G, Nei M, Kumar S: MEGA5: Molecular Evolutionary Genetics Analysis Using Maximum Likelihood, Evolutionary Distance, and Maximum Parsimony Methods. Mol Biol Evol 2011, 28:2731-2739.

75. Kämper J, Kahmann R, Bölker M, Ma $\sqcup$, Brefort T, Saville BJ, Banuett F, Kronstad JW, Gold SE, Müller O, Perlin MH, Wösten HA, de Vries R, RuizHerrera J, Reynaga-Peña CG, Snetselaar K, McCann M, Pérez-Martín J, Feldbrügge M, Basse CW, Steinberg G, Ibeas Jl, Holloman W, Guzman P, Farman M, Stajich JE, Sentandreu R, González-Prieto JM, Kennell JC, Molina L, Schirawski J, Mendoza-Mendoza A, Greilinger D, Münch K, Rössel N, Scherer M, Vrane M, Ladendorf O, Vincon W, Fuchs U, Sandrock B, Meng S, Ho ECH, Cahill MJ, Boyce KJ, Klose J, Klosterman SJ, Deelstra HJ, OrtizCastellanos L, Li W, Sanchez-Alonso P, Schreier PH, Häuser-Hahn I, Vaupel M, Koopmann E, Friedrich G, Voss H, Schlüter T, Margolis J, Platt D, Swimmer C, Gnirke A, Chen F, Vysotskaia V, Mannhaupt G, Güldener U, Münsterkötter M, Haase D, Oesterheld M, Mewes HW, Mauceli EW, DeCaprio D, Wade CM, Butler J, Young S, Jaffe DB, Calvo S, Nusbaum C, Galagan J, Birren BW: Insights from the genome of the biotrophic fungal plant pathogen Ustilago maydis. Nature 2006, 444:97-101.

76. Gao Q, Jin $K$, Ying SH, Zhang Y, Xiao G, Shang Y, Duan Z, Hu X, Xie XQ, Zhou G, Peng G, Luo Z, Huang W, Wang B, Fang W, Wang S, Zhong Y, Ma LJ, St Leger RJ, Zhao GP, Pei Y, Feng MG, Xia Y, Wang C: Genome Sequencing and Comparative Transcriptomics of the Model Entomopathogenic Fungi Metarhizium anisopliae and M. acridum. PLoS Genet 2011, 7:e1001264.

77. Ispolatov I, Yuryev A, Mazo I, Maslov S: Binding properties and evolution of homodimers in protein-protein interaction networks. Nucleic Acid Res 2005, 33:3629-3635.

78. D'Souza DT, Tiwari R, Sah AK, Raghukumar C: Enhanced production of laccase by a marine fungus during treatment of colored effluent and synthetic dyes. Enzyme Microb Technol 2006, 38:504-511.

79. Okino LK, Machado KMG, Fabric C, Bonomi VLR: Ligninolytic activity of tropical rainforest basidiomycetes. World J Microbiol Biotech 2000, 16:889-893.

80. Archibald FS: A new assay for lignin-type peroxidases employing the dye azure B. Appl Environ Microbiol 1992, 58:3110-3116.

doi:10.1186/1471-2164-13-493

Cite this article as: Islam et al:: Tools to kill: Genome of one of the most destructive plant pathogenic fungi Macrophomina phaseolina. BMC Genomics 2012 13:493. 